JOURNAL DE PHYSIQUE

Colzoque C5, supplément au n'12, Tome 43, décembre 1982

page $\mathrm{C} 5-259$

\title{
MULTICHAMBER REACTORS : A SOLUTION TO THE PROBLEM OF GRADED HETEROINTERFACES IN HOT-WALL VPE SYSTEMS
}

\author{
G. Beuchet, D. Clemensat and P. Thebault \\ Thomson-CSE, Laboratoire Central de Recherches, Domaine de Corbevizze, \\ B.P. $N^{0} 10,91401$ Orsay Cedex, France
}

Résumè. - La production de couches homoépitaxiques de bonne qualité par la méthode de croissance dite "des hydrures" est une technique bien connue en ce qui concerne les binaires III- $V$ les plus répandus. Cependant, il est difficile d'obtenir des hêtérointerfaces abruptes entre par exemple Ga In As et In $\mathrm{P}$, l'écoulement du flux gazeux étant gênéralement lent afin de suivre le profil de température voulu entre sources et substrat. Dans des conditions d'utilisation normales, un changement de composition correspondrait à un temps équivalent à la croissance de plusieurs milliers d'Angströms de matëriau.

Ce papier décrit l'obtention d'hétérojonctions abruptes obtenues dans un nouveau type de réacteur, comprenant quatre chambres de croissance indépendantes, où peuvent être établies des conditions de flux gazeux en état stationnaire et les changements de composition sont obtenus en déplaçant rapidement I'échantịion d'une chambre à l'autre. Il a été possible, avec ce réacteur, d'obtenir des largeurs d'interfaces de l'ordre de $150 \AA$.

Abstract. - The "hydride" growth process is well established as a technique for producing high quality homoepitaxial lavers of the common III-V binary materials. However, it is difficult to obtain abrupt heterointerfaces for example between $\mathrm{Ga}$ In $\mathrm{As}$ and In $\mathrm{P}$, as the gas speed is generally slow in order for the gas to follow the desired temperature profile in its passage through the source to substrate. Thus under normal conditions, a change of composition will occur in a time corresponding to the growth of several thousands of angströms of material.

This paper describes the growth of abrupt heterojunctions which have been achieved in a new geometry reactor, based on four separate growth chambers. In each chamber, the gas flow conditions for the growth of a specific composition are stabilised and changes of composition are achieved by rapidly moving the sample from one chamber to another. This new reactor has allowed us to grow multiple heterojunctions with an interface abruptness of better than $150 \AA$.

1. Introduction. - The "hydride" vapor phase epitaxy of (Ga, In) (As, P) alloys is a well-known method (1-5), which consist of a hot-wall reactor working at atmosoheric pressure. The gaseous snecies are synthetized in a high-temperature region by reacting hydrogen chloride with liquid Indium and Gallium sources, and pyrolysing Arsine and Phosphine downstream. Then the gas flow is cooled by a negative temperature gradient which is imposed between the sources and the substrate. This cooling of the gazeous phase results in growth onto the substrate.

The use of heterostructures for the fabrication of devices requires lattice matching on the substrate, and very sharp interfaces between different layers. As the gas flow has to follow the desired temperature profile, the gas velocities are usually very low and the compositional change of the gas phase becomes very slow. An alternative to overcome this problem is to use 
multichamber reactors (5-7), where the substrates are moved between different steady state gas phase compositions.

2. Princinle of conventional hydride-VPE growth of III-V alloys and kinetic Timitations

A sketch of a conventional reactor is given in fig. 1 .

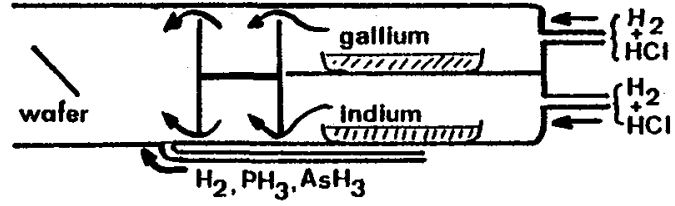

Fig. 1: Conventiona 1

Hydride VPE reactor

This reactor usually consists in a fusedsilica tube heated by a multizone furnace which impose a negative temperature gradient between two regions.

a/ In the source region $\left(750-900^{\circ} \mathrm{C}\right)$, all the gazeous groun II I species necessary for the growth are formed by reacting Hydrogen chloride $\mathrm{HCl}$ diluted in Hydrogen with liquid Indium and Gallium. These metallic sources are usually separated in two different boats, but In-Ga melts have been used (8-9).

Arsine $\left(\mathrm{As}_{3}\right)$ and Phosphine $\left(\mathrm{PH}_{3}\right)$ are introduced downstream and are pyrolysed in Arsenic and Phosphorus vapours.

The synthesis of $\mathrm{Ga} \mathrm{Cl}$, In $\mathrm{Cl}, \mathrm{P}_{\text {vap }}$, As ${ }_{\text {vap }}$ can be described by the following set of chemical reactions :

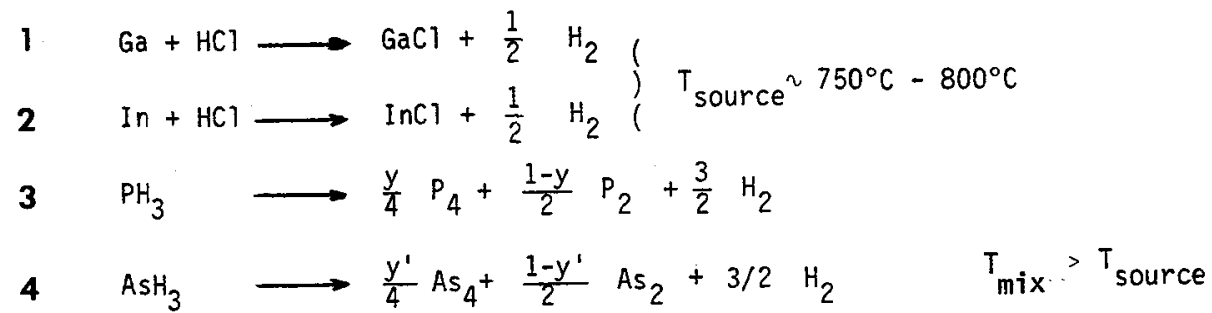

The resulting gas phase is assumed to be in themodynamic equilibrium (9-13). The proximity of thermodynamic equilibrium is almost obtained for the group $V$ compounds, as reactions 3 and 4 are homogeneous decompositions in the gas phase (first order reactions). This condition is quite difficult to achieve for reactions 1 and 2 . The quasi-equilibrium is obtained in a narrow partial pressure range which depends on : 
- source geometry

- total gas flow rate

- reactor design

- kinetics of reactions 1 and 2

As reactions 1 and 2 are heterogeneous reactions between a gas and a liquid, kinetics are greatly influenced by the geometry.

In order to obtain a yood reproducibility, it is better to be in quasi-equilibrium conditions and therefore, to use

- large liquid/gas contact areas.

- boat shaves which increase the contact duration between gazeous products and liquids.

- relatively low flow velocities.

Figure 2-a shows that the arowth rate of In $P$ is significantly changed by the design of the boats which contain the In source.

b/Assuming that the previously described conditions are carried out, the gas phase is swept downstream in a temperature gradient $\left(\tau-10^{\circ} \mathrm{C} / \mathrm{cm}\right)$, in order to obtain a metastable equilibrium. This cooling of the nutrients results in growth onto the substrate, which can be described by :

(5) $\frac{1}{2} \mathrm{H}_{2}+\mathrm{GaCl}+\frac{\mathrm{u}}{4} \mathrm{As}_{4}+\frac{1-\mathrm{u}}{2} \mathrm{As}_{2} \longrightarrow \mathrm{GaAs}+\mathrm{HCl}$

(5') $\frac{1}{2} \mathrm{H}_{2}+$ In $\mathrm{Cl}+\frac{\mathrm{v}}{4} \mathrm{P}_{4}+\frac{1-\mathrm{v}}{2} \mathrm{P}_{2} \longrightarrow$ In $\mathrm{P}+\mathrm{HCl}$

A11 the pseudo-binary system Ga $\mathrm{In}_{1-\mathrm{x}} \mathrm{As}_{y} \mathrm{P}_{1-y}$ can be covered with an appropriate ratio between (5) and (5').

In VPE reactors, these reactions occur far from equilibrium and the growth is significantly influenced by kinetics and parasitic effects (14), as :

- substrate orientation.

- nucleation on the walls of the reactor.

- mass transport (convective or diffusive flows).

The parasitic nucleation on the walls can be minimized, using an excess of $\mathrm{HCl}$, but mass transfer is clearly responsible for reproducibility, even in the case of homoenitaxy (figure 2-b). The flows must be carefully adjusted a long time before growth, in order to increase the reproducibility.
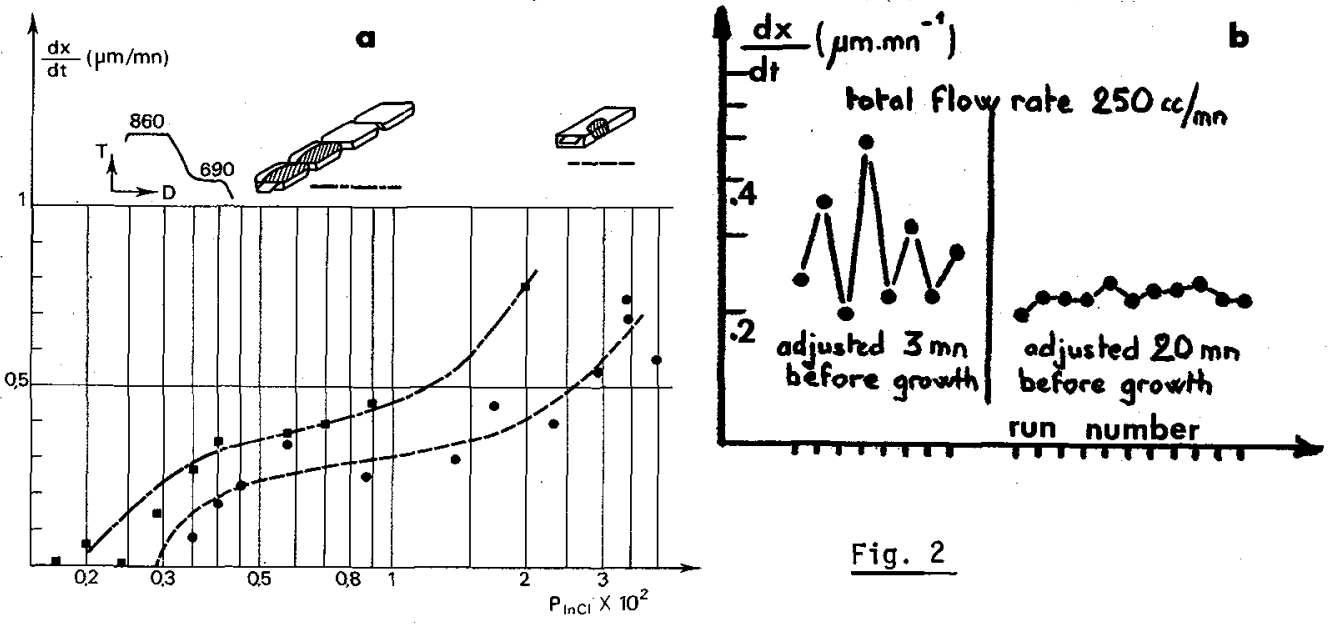

Fig. 2 


\section{Hetero interfaces obtained in conventional and multichamber reactors}

a/ Figure 3 shows the three important mecanisms involved in CVD growth processes, i.e.:

- mass transport.

- heterogeneous chemical reactions, where liquid/gas and solid/gas interfaces are involved.

- homogeneous chemical reactions, taking place in the gas phase.

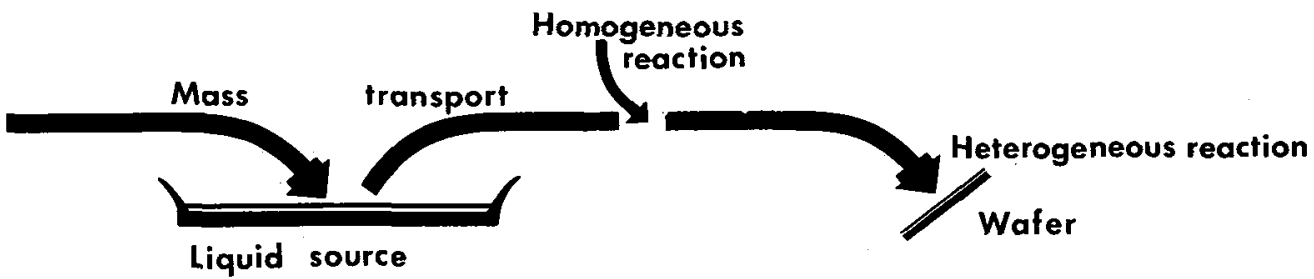

Fig. 3: V.P.E. mecanisms

Homogeneous reactions are usually well described by thermodynamic analysis, because they take place in the gazeous phase, where the reaction kinetics are rapid, and the system is well defined when the free energy function $G\left(T, P, n_{i}\right)$ is a minimum. The definition of a system by minimisation of its free energy gives a set of $n_{j}$ values which are only dependant upon the pressure, the temperature and the composition of the nutrient phase, or the initial composition of the system before reactions occur.

Heterogeneous growth reactions are involved in mass transfer and chemical reactions which take place at surface sites. These chemical reactions only depend on the concentration of the reacting snecies in the nutrient phase, on the coverage ratio of the active surface, and on adsorption and desorption energies; kinetics are usually more rapid than mass transfer during composition changes ; otherwise, they are time-independent, and have been studied by statistical physics and the theory of rate processes (15-17).

b/ The only time dependent parameter in crystal growth is mass transport, assuming that heat transfers are in steady-state (18-19). In a multicomponent non isothermal fluid, mass, momentum and energy are conservative, and the continuity equation, which takes into account the convective and diffusive fluxes, expresses the local gain of mass density for each species $i$, due to convection $v$ and diffusion $j_{i}$ :

$$
\frac{\partial \rho_{i}}{\partial t}=-\operatorname{div}\left[\rho_{i} \vec{v}+\overrightarrow{j_{i}}\right]
$$

The diffusive flux $j_{i}$ is a combination of two terms : concentration gradient-induced diffusion and thermal diffusion :

$$
\overrightarrow{j_{i}}=-\frac{c^{2} M i M M}{\rho} D_{i, M}\left[\overrightarrow{\operatorname{grad}}\left(x_{i}\right)+k_{T} \overrightarrow{\operatorname{grad}}(\operatorname{In} T)\right]
$$

where : $M i$ is the molar mass of $i$

$M_{w}$ is the molar mass of the main gas

$D_{i, M}$ is the mutual diffusion coefficient of $i$ and $M$

$X i$ is the molar fraction of $i$ 
$K_{T}$ is the thermal diffusion coefficient

$\rho, \rho i$ are the average and $i-t h$ species mass density

This differential equation can be computed and gives the spatial and time-dependent concentration of each species.

Figure 4 shows the response of the gas phase composition in the reactor (assumed to be cylindrical), without taking into account the chemical reactions and temperature gradient, when a new gas is introduced in the reactor at the time $t_{0}$.

Fig. 4: Diffusion in the gas phase

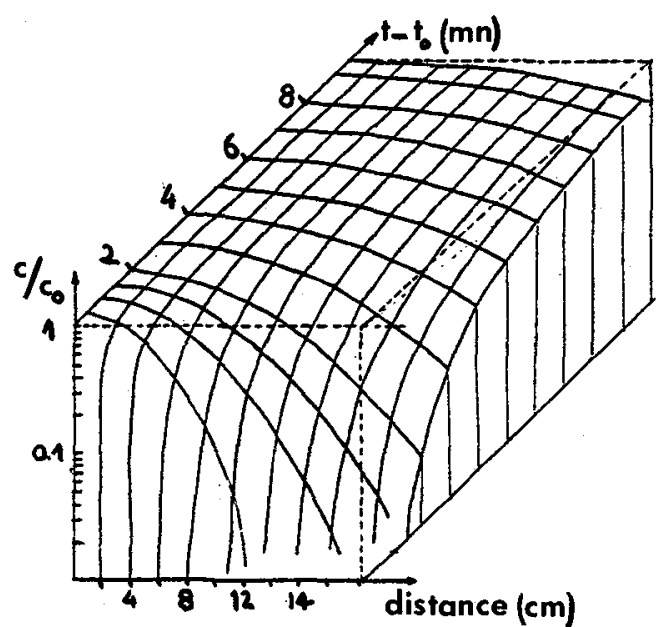

This simplified example gives an idea of the influence of transient mass transfer and clearly demonstrates the difficulty of growing binary or quarternary material directly on In $P$, as a steady state after gas switching is not reached within a few minutes.

A solution to overcome this problem is to use a "waiting chamber", where the sample is covered and/or protected by the appropriate amount of arsine and phosphine until the steady state is reached.

An alternative is to use a multichamber reactor (figure 5), which allows the growth of a complete double heterostructure in a single run.

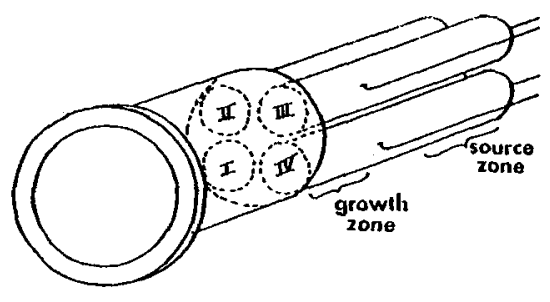

a

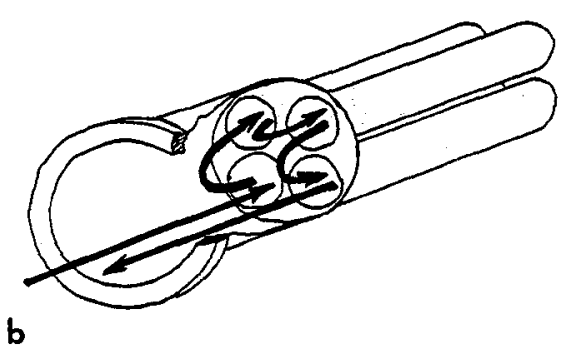

Fig. 5: Four chamber-reactor

a- Organisation

b- Double heterostructure growth sequence 
This reactor is comnosed of four parallel and independent VPE reactors ("chambers") where all the facilities for gas supplying and monitoring are set up. Each chamber contains two separate In and Ga boats, except for the etching chamber, where the substrate surface is etched before growth. Therefore, it is possible to adjust in each chamber the appropriate gas phase composition in order to grow any solid Ga $\mathrm{In}_{1-x} \mathrm{As}_{y} \mathrm{P}_{1-y}$ material, and to be in steady state before any growth.

These four chambers are linked downstream by a fith common tube, in order to transfer the samnle from one chamber to another. This is achieved by using an automatic transfer mecanism, which makes the movement possible within two seconds (figure 6).

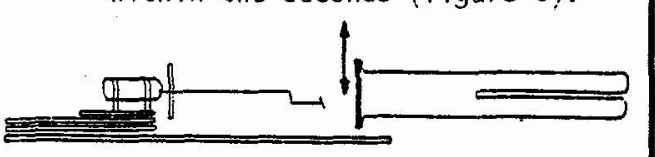

sample loading and unloading

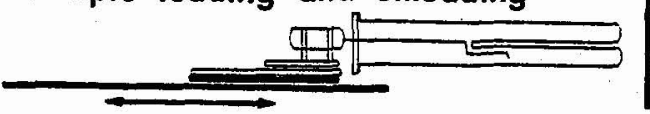

Fig. 6

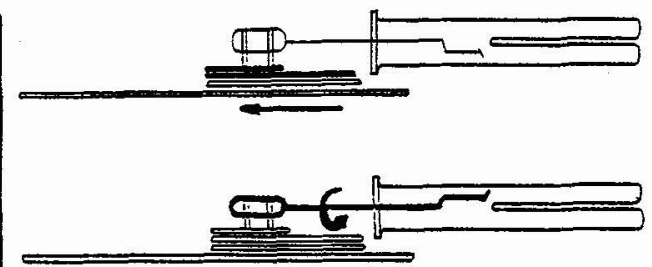

transfer during growth

During these two seconds, assuming that a denosit occurs during the passage in the common tube with the usual growth rate, the perturbed interface should have a thickness of $\sim 100-150 \AA$.

In order to characterize these heterointerfaces, beve1s are chemically etched, usinn a $\mathrm{Br}_{2}$ - methanol solution $(20,21)$. Using this technique, it is nossible to observe the evolution of defects in each layer and at the heterointerfaces. The comnosition of the different lavers which have been revealed on the bevel is analysed by scanning Auqer spectroscony, as shown in fiqure 7 .

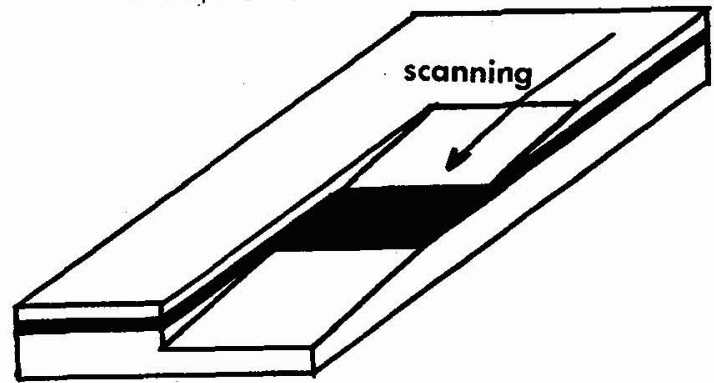

Fig. 7: Auger spectroscopy

The results obtained are in good agreement with the assumntion of a continuous denosit during the transfer of the samnle. Finure 8-a shows the heterointerface abruptness obtained on a In $P / Y_{3}$ In As heterostructure grown in this reactor using a transfer duration of 5 seconds, by analysing the Arsenic concentration on a bevel ann?e of $0.17^{\circ}$. The interface abruntness is $190 \AA$, but it can be seen that the sianal transition is composed of three varts with different slones, and the real thickness might be less than $150 \AA$. Figure 8-b represents the Phosnhorus ana?ysis of a double heterostructure for laser application. The two interfaces are less than $100 \AA$. 

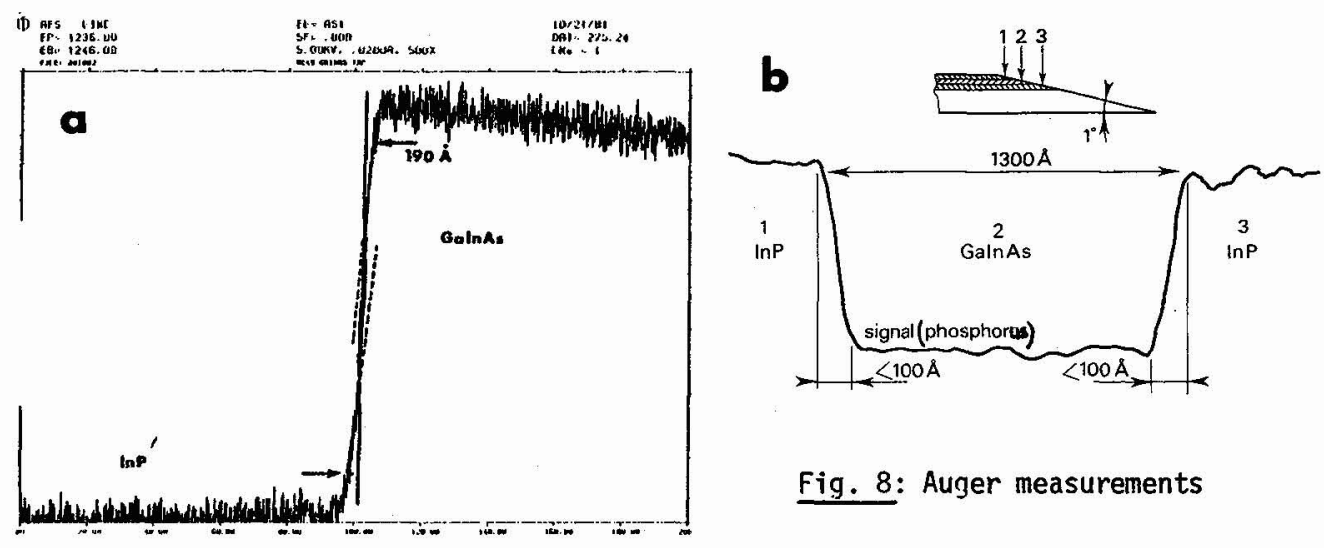

In order to test the properties of these double heterostructures, broad area lasers have been fabricated (22) ; the current densities of $2 \mathrm{KA} / \mathrm{cm}^{2}$ which have been measured demonstrate that the nroperties of these interfaces are nuite good.

4. Conclusion - The nurnose of this study was to demonstrate that changes of the has composition for growing heterostructures cause non-steady state mass transfer in a VPE-reactor, and that this is not convenient for arowing double heterostructures, as the samnle has to be nrotected untfl steady states conditfons are obtalned. It has been shown that the use of a four chamber reactor was a good alternative to obtain sharp interfaces wi thout degrading the nronerties of the materials. The interfaces sharnness obtained are about 100 " $150 \AA$, and by using lower growth rates, can be probably reduced.

Aknowledgments The authors are grateful to $G$. Laurencin and $R$. Bisaro for bevel and Auger assesments. They wish to thank $M$. Razenhi and $B$. Lent for very helnfull discussions.

\section{References}

(1) R.R. Saxena, S.B. Hyder, P.E. Greqory and J.S. Esher, J. of Crystal Growth 50 (1981) 481.

(2) L.M. Zinkiewicz, T.J. Roth, B.J. Skromme and F.E. Stillman, in : Proc. 8 th Intern. Symn. on fia As and Related Comnounds, Vienna, 1980 Inst. Phys. Conf. Ser. 56 (Inst. Phys. London, 1981) ? 19.

(3) K. Suqiyama, H. Ko.jima, H. Enda and M. Shibata, Janan. J. Annt. Phys. 16 (1977) 2197.

(4) H. Enda, Janan J. Annl. Phys. 18, 11 (1979) 2167.

(5) F.H. OIsen and T.J. Zamerowski, Progr. Crystal Frowth Characterization ? (1979) 309 .

(6) T. Mizutari, M. Yoshida, A. Usui, H. Hatanabe, T. Yuasa and I. Hayashi, Jaban. J. Annt. Phys. 19 (1980) 113.

(7) F. Beuchet, M. Bonnet, P. Thëbau1t and J.P. Duchemin, in :

Proc. 8 th Intern. Symn. on fa As and Related Comnouds, Vienna, 1980, Inst. Phys. Conf. Ser. 56 (Inst. Phys, London, 1981) p 37. 
(8) P. Kordos, P. Schumbera, M. Heyen and P. Balk, to be published

(9) A.J. Chatterjee, M.M. Faktor, M.H. Lyons and R.H. Moss, J. of Crystal frowth 56 (1.982) 591.

(10) D.W. Shaw, J. Phys. Chem. Solids 36 (1975) 111.

(11) H. Nagai, J. Electrochem. Soc. 1268 (1979) 1400.

(12) A. Koukitu and H. Seki, J. of Crystal frowth 49 (1980) 325.

(13) S. Franchi, C. Pelosi and F. Attolini, Revue de Phys. Anpliauée 16 (1981) 1 .

(14) T. Mizutani and H. Watanabe, to be published.

(15) S. Filasstone, K.J. Laidlerand H. Eyring, the theory of rate processes (MC Graw-H111, N.Y. 1941).

(16) R. Cadoret and M. Cadoret, J. of Crystal frowth 31 (1975) 142.

(17) J.L. Laporte, M. Cadoret and R. Cadoret, J. of Crystal farowth 50 (1980) 663.

(I8). F. Rosenberger, Fundamentals of Crystal Growth I (Snringer-Verlaa, Beriin, 1979).

(19) M.L. Hitchman, J. of Crysta] Growth 48 (1980) 394.

(20) R. Bisaro, Gourencin, A. Friederich, M. Razeghi, Annl. Phys. Lett.

40 (1982)' 978 .

(21) A.M. Huber, G. Laurencin, A. Friederich, to be published.

(22) F. Beuchet, M. Bonnet, P. Thébault and J.P. Duchemin, J. of Crystal frowth 57 (1982) 379 . 